\title{
Submucosal lesion of the oesophagus: not everything is what it seems
}

\author{
Ana Franky Carvalho, ${ }^{1,2}$ Ana Joao Rodrigues, ${ }^{2}$ Nuno Sousa, ${ }^{2}$ Pedro Leão ${ }^{1,2}$
}

${ }^{1}$ Department of General Surgery, Hospital of Braga, Braga, Portugal LLife and Health Sciences Research Institute (ICVS), School of Health Sciences, University of Minho, Braga, Portugal

\section{Correspondence to}

Professor Pedro Leão, pedroleao@ecsaude.uminho.pt

Accepted 18 August 2014

\section{DESCRIPTION}

A 32 years-old woman with a history of depression, visited her doctor for heartburn and postprandial fullness with 2 months of evolution, possibly due to the consumption of non-steroid antiinflammatory drugs due to knee pain. Upper endoscopy (figure 1A) revealed a $20 \mathrm{~mm}$ submucosal procidentia covered with normal mucosa (most likely a submucosal tumour like) located $30 \mathrm{~cm}$ from the dental arch. An esophageal gastrografin swallow revealed a diverticular lesion (figure 1D). The endoscopic ultrasound revealed that it was an esophageal mesenchymal tumour-likely leiomyoma (figure 1B). CT confirmed the previous hypothesis (figure 1C). The patient underwent tumour enucleation by thoracotomy (figure 2A).

A detailed anatomopathological analysis revealed an esophageal duplication cyst (CDE; figure 2B). The patient was discharged on the third postoperative day with no symptoms, tolerating soft diet. After 3 years of follow-up the patient is still asymptomatic.

The first case of CDE was described by Blasius in 1711. ${ }^{1}$ The pathogenesis of this rare disease involves the incomplete embryological recanalisation of the upper digestive tract with subsequent coalescence of vacuoles. ${ }^{2}$ It is characterised by presenting pseudostratified columnar and ciliary epithelium (asterisk in figure 2B) and two layers of smooth muscle. The preferred location is in the distal thoracic oesophagus and in $90 \%$ of cases there is no communication with the oesophagus. Owing to the potential compression, haemorrhage, infection or malignancy of the cyst, the treatment of choice is surgery, regardless of the presence or absence of symptoms. The differential diagnosis includes bronchogenic cyst. ${ }^{3}$ This is distinguishable from the CDE histologically by the presence of cartilage.
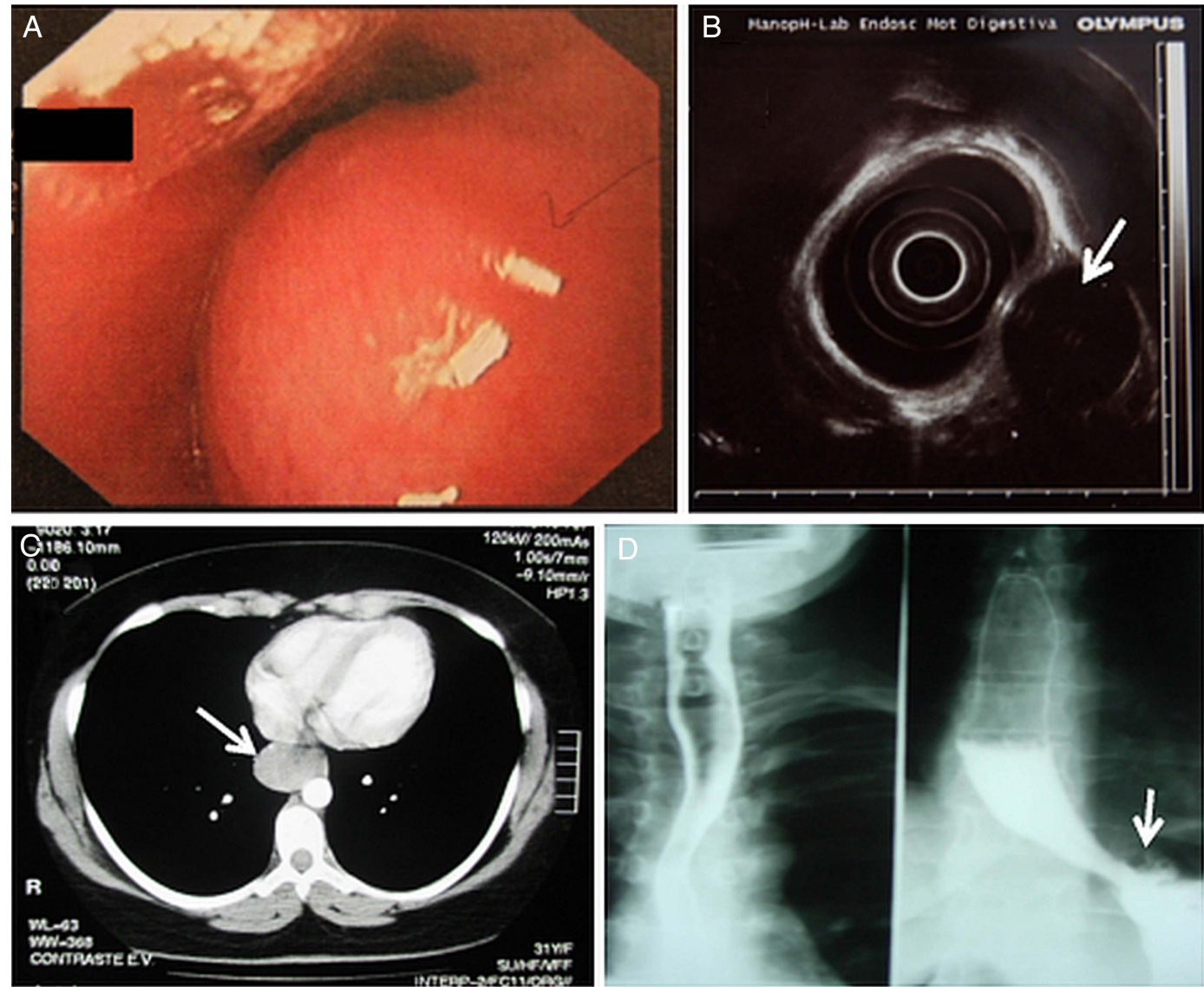

Figure 1 Complementary examinations: (A) upper endoscopy show a submucosal lesion in the lumen of oesophagus. (B) Endoscopic ultrasound revealed a likely esophageal mesenchymal tumour (arrow). (C) CT scan shows a tumour of the submucosal layer of the oesophagus like leiomyoma (arrow). (D) Esophageal gastrografin swallow revealed a subtraction image compatible with diverticular lesion (arrow). 
Figure 2 (A) Esophageal duplication cyst in loco. (B) Anatomopathological analysis revealed an esophageal duplication cyst.
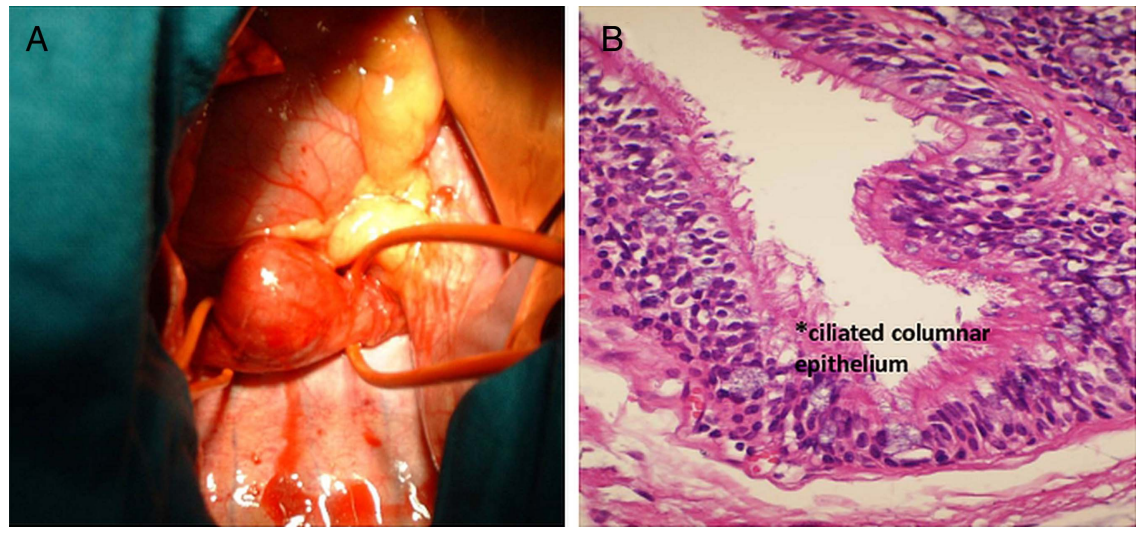

Competing interests None.

Patient consent Obtained.

Provenance and peer review Not commissioned; externally peer reviewed.

- Symptoms are caused by compression of surrounding structures.

- Maldevelopment of the posterior division of the primitive foregut is responsible for esophageal cysts.

- The principal differential diagnosis is bronchogenic cyst.

Contributors AFC and PL acquired the data and performed its analysis and interpretation. AJR, NS and PL wrote the manuscript and provided support for the study.

Copyright 2014 BMJ Publishing Group. All rights reserved. For permission to reuse any of this content visit

http://group.bmj.com/group/rights-licensing/permissions.

BMJ Case Report Fellows may re-use this article for personal use and teaching without any further permission.

Become a Fellow of BMJ Case Reports today and you can:

- Submit as many cases as you like

- Enjoy fast sympathetic peer review and rapid publication of accepted articles

- Access all the published articles

- Re-use any of the published material for personal use and teaching without further permission

For information on Institutional Fellowships contact consortiasales@bmjgroup.com

Visit casereports.bmj.com for more articles like this and to become a Fellow 